by Hisashi Nirei ${ }^{1 *}$, Osamu Kazaoka ${ }^{2}$, Masaaki Uzawa ${ }^{3}$,Tomoyo Hiyama ${ }^{3}$, Jonas Satkunas ${ }^{4}$,

and Muneki Mitamura ${ }^{5}$

\title{
Erratum to: Observations on seismically induced liquefac- tion-fluidization in reclaimed land at Hinode, Honshu, Japan
}

${ }^{1}$ Japan Branch of International Union of Geological Sciences, Commission on Geoscience for Environmental Management (IUGS-GEM), 1277-1 Kamayauchi, Motoyahagi, Katori City, Chiba Prefecture 287-0025, Japan; The Geo-pollution Control Agency, Japan; *Correponding author,E-mail:nireihasashi@msn.com

${ }^{2}$ Research Institute of Environmental Geology, Chiba, Japan, E-mail: osamu.kazaoka@gmail.com

${ }^{3}$ Kanto-Kensentsu Co., 699 Mobara, Mobara City, Chiba 297-0026, Japan, E-mail: t.hiyama@k-and-o-energy.co.jp

${ }^{4}$ Geological Survey of Lithuania, Vilnius, Lithuania,E-mail: jonas.satkunas@lgt.lt

${ }^{5}$ Osaka City University, Osaka, Japan, E-mail: mitamura@sci.osaka-cu.ac.jp

\section{Erratum to: Episodes, December 2016, v. 39, no. 4, pp. 568-581.}

DOI:10.18814/epiiugs/2016/v39i4/103889

There is an error in Figure 16 in page 576. It is the same as Figure 15 in page 575 . Therefore, Figure 16 has to be changed into following figure.

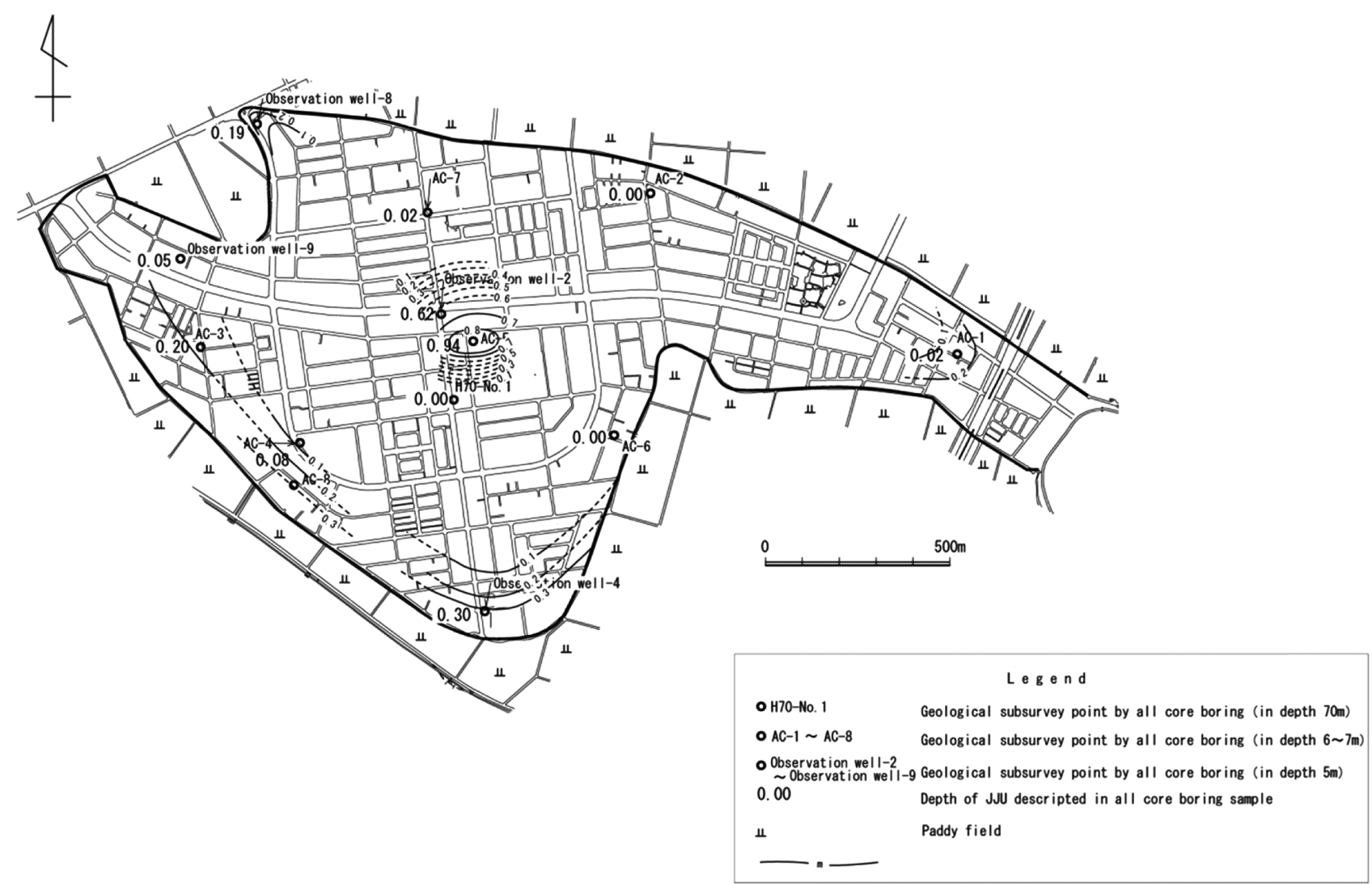

Figure 16. Isopach map of the Downstream Material Layer (DML).

The original article can be found under http://dx.doi.org/10.18814/ epiiugs/2016/v39i4/103889 